\title{
Manipulation of Whole-vine Carbon Allocation Using Girdling, Pruning, and Fruit Thinning Affects Fruit Numbers and Quality in Kiwifruit
}

\author{
Linda M. Boyd ${ }^{\mathbf{1}}$ \\ The New Zealand Institute for Plant and Food Research Limited, Plant \& \\ Food Research Mt Albert, Private Bag 92169, Auckland Mail Centre, 1142, \\ Auckland, New Zealand
}

\section{Andrew M. Barnett \\ Plant \& Food Research Te Puke, 412 No 1 Road, RD 2, Te Puke, New Zealand}

Additional index words. leaf-to-fruit ratio, maturity, storage disorders

\begin{abstract}
We compared the long-term effects of whole-vine source-sink manipulation on yield, composition, and quality of fruit from mature field-grown kiwifruit (Actinidia chinensis Planch. var. chinensis) 'Hort16A' vines. Four contrasting source/sink-modifying treatments were applied to vines each year from Spring 2003 to 2007: 1) control-standard canopy management techniques, no trunk girdle; 2) extended trunk girdle (ETG) — girdle was opened in late summer, kept open over winter, and allowed to heal the next spring; 3) "feast"-cropload was kept low and leaf numbers kept high, no trunk girdle; and 4) "famine"-fruit numbers were kept high and vines were heavily pruned to stimulate regrowth, no trunk girdle. Fruit from the famine vines were smaller with lower dry matter concentration (DMC; dry weight as a percentage of fresh weight) and had delayed maturity relative to fruit from the control vines. Return bloom was reduced in the famine vines, resulting in $\approx \mathbf{4 2} \%$ less fruit in the famine vines compared with the feast vines, and this difference remained consistent across all three seasons. Fruit from the feast treatment were larger with advanced maturity relative to fruit from control vines; there were no differences in fruit numbers in subsequent seasons. Fruit DMC was higher and maturity was advanced in the ETG vines relative to the control vines. Fruit numbers in the ETG vines consistently increased relative to the control vines each season. There were no consistent treatment effects on fruit mineral concentrations, except that fruit from the feast vines had higher nitrogen concentrations than fruit from the famine vines. Seasonal variation in the incidence of storage disorders was large; in years when disorders were present, physiological pitting incidence was higher in fruit from the treatments that advanced maturity and the incidence of low temperature breakdown was highest in treatments that delayed maturity. Although the treatments affected vine productivity, fruit DMC, and storage performance, there was no evidence of a gradual decline in quality and productivity after 4 years of treatment application.
\end{abstract}

Kiwifruit growers need to consistently produce high yields of kiwifruit with high $\mathrm{DMC}$ to meet consumer preferences for fruit with intense flavor and sweetness (Harker et al., 2009) without compromising storage quality. Mature kiwifruit vines allocate $\approx 50 \%$ of annual newly fixed biomass to fruit each season (Boyd et al., 2010; Clark and Smith, 1992). This figure is relatively low compared with some perennial fruit crops; in apples, for example, $70 \%$ of annually fixed biomass

\footnotetext{
Received for publication 5 May 2010. Accepted for publication 24 Jan. 2011.

This project was funded by the Plant \& Food Research Kiwifruit Royalty Investment Programme. We thank Tim Holmes and Philip Martin for technical assistance and Mike Currie and Grant Thorp for their helpful suggestions.

${ }^{1}$ To whom reprint requests should be addressed; e-mail linda.boyd@plantandfood.co.nz.
}

is allocated to fruit (Heim et al., 1979). The kiwifruit vine is a climbing or straggling plant (Ferguson, 1990) and requires careful canopy management to maintain yields and fruit DMC while controlling canopy vigor. Vine management practices routinely used include trunk girdling, attention to summer pruning, and growing fruit on older, less vigorous wood (Cooper and Marshall, 1991; Davison, 1990; Goren et al., 2004; Miller et al., 2001). A primary aim of these techniques is to minimize competition for resources between fruit and rapidly growing shoots.

Perennial plant responses to excessive defoliation, whether caused by harsh pruning, herbivory, or frost, include reallocation of resources toward shoots at the expense of root or reproductive growth. Badly timed or excessive pruning can reduce fruit DMC, delay maturity, and reduce concentrations of inorganic nutrients in fruit (Candolfi-Vasconcelos and Koblet,
1990; Siham et al., 2005; Valladares et al., 2007). Trunk girdling interrupts the phloem connection between the canopy and roots affecting the transport of carbohydrates and plant growth regulators from canopy to the roots (Goren et al., 2004). There is little published information on the effects of trunk girdling in kiwifruit vines, although Davison (1990) reported that girdling advanced fruit maturity in the year of girdle application and enhanced flower numbers in the season after girdle application. The effects of girdling on fruit production in other fruit crops include increased fruit set, increased fruit size, and advanced fruit maturity (Goren et al., 2004). It is not clear exactly how girdling affects fruit set and development, but the increased availability of carbohydrates in the canopy and the altered supply of root-generated hormones are both likely to be involved (Cutting and Lyne, 1993; Harrell and Williams, 1987).

Kiwifruit can be cool-stored for several months after harvest but can be affected by storage disorders such as low temperature breakdown. Both fruit maturity at harvest and fruit concentrations of inorganic nutrients can affect storage quality in kiwifruit (Clark et al., 2004; Ferguson et al., 2003). However, there is little information about whether vine management techniques implemented to improve kiwifruit DMC also affect fruit maturity and composition and, ultimately, storage performance.

This long-term study was established on mature, field-grown 'Hort16A' kiwifruit vines using different techniques (e.g., pruning, fruit thinning, and girdling) to modify whole-vine resource allocation. High croploads combined with badly timed and excessive pruning were used to deplete whole-vine carbohydrate status (the famine treatment), low croploads with high leaf to fruit numbers were used to provide abundant carbohydrates to fruit (feast treatment), and trunk girdling was used to isolate the canopy from the roots for extended periods of time. The famine and ETG treatments were designed to identify any problems that may occur if growers channel too much assimilate into fruit production. The aim of the project was to determine how such treatments affected vine productivity, fruit DMC, and storage performance over several seasons.

\section{Materials and Methods}

Experimental design. Forty mature kiwifruit vines, Actinidia chinensis Planch. var. chinensis 'Hort16A', were selected from three adjacent rows of vines growing at the Te Puke Research Center in the Bay of Plenty, New Zealand (lat. $37^{\circ} 49^{\prime} \mathrm{S}$; long. $176^{\circ} 19^{\prime} \mathrm{E}$ ). The vines were planted in 1993 and the 'Hort16A' scion was grafted onto the rootstock in 1996. The vines had been trained onto a pergola system and each vine had $\approx 30 \mathrm{~m}^{2}$ of canopy area with a planting distance of $6 \mathrm{~m}$ and row spacing of $5 \mathrm{~m}$. The vines were randomly assigned to one of four treatments: control, ETG, feast, or famine, with 10 replicate vines per treatment. The feast and famine terminology is that used by Koch (1996). 
Treatment application. Each spring (November to December, when mean fruit fresh weight was $\approx 30 \mathrm{~g}$ ) fruit counts were carried out on all treatments as a measure of potential vine productivity and so that the control and ETG vines could be thinned to give similar croploads to each other. The adjusted cropload in the control and ETG vines was typically 40 to 50 fruit $/ \mathrm{m}^{2}$, except in 2006 , when the adjusted cropload was nearer 70 fruit $/ \mathrm{m}^{2}$. In the feast treatment, leaf-to-fruit ratios were kept high by pruning fruiting shoots to approximately six leaves past the last fruit in mid-November and by thinning fruit to one per shoot in December $(\approx 1500$ fruit removed from each vine, cropload reduced from $\approx 75$ to $\approx 28$ fruit $/ \mathrm{m}^{2}$ ). In the famine treatment, leaf-to-fruit ratios were kept low by carrying out little or no spring fruit thinning, removing all non-fruiting shoots in December, and pruning fruiting shoots to one leaf past the last fruit. The pruning and thinning treatments were first applied in late Dec. 2003.

In addition, standard summer pruning was applied to all treatments; unwanted shoot growth was removed at regular intervals (November to March). In the famine treatment, the summer pruning took place 2 weeks later than in the other treatments; this allowed growing shoots to continue to use resources before becoming sources, exacerbating the whole-vine carbohydrate depletion.

The first trunk girdle was applied to the ETG vines each February, $\approx 120 \mathrm{~d}$ after midbloom (late summer, first application in Feb. 2004) by removing a 5 -mm wide strip of bark from the scion of each vine (Fig. 1). Over fall (March and April), the girdles were reopened as they began to heal. The girdles were then allowed to heal over with the healing occurring in late spring (October to November; Fig.

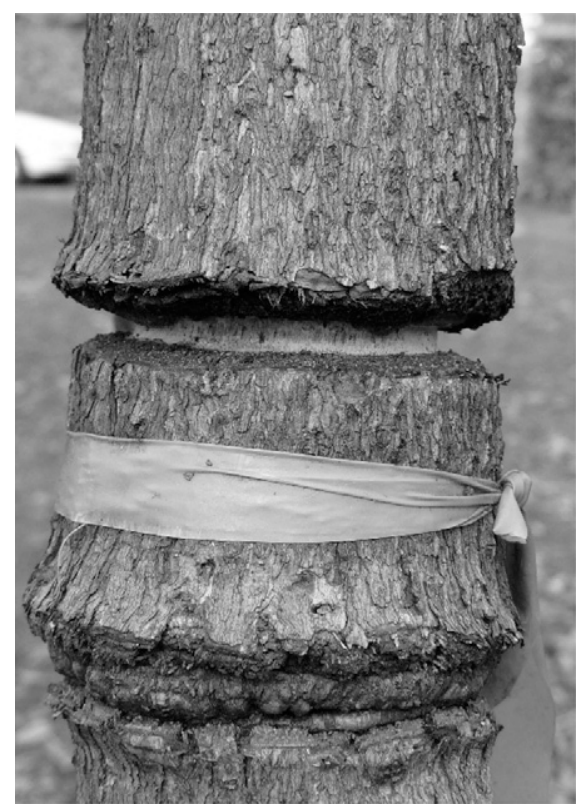

Fig. 1. An unhealed trunk girdle (above the tape) photographed in Oct. 2006, 8 months after the girdle was first applied. Below the tape is a healed girdle from the previous season.
1). In 2005 (the second season of study), the girdles were not reopened after the initial February girdle because of concerns for vine health and survival.

Fruit sampling and analysis. Fruit were harvested on the same date, when fruit flesh from the famine vines (the latest maturing treatment) had begun to lose their green color (i.e., mean flesh hue angle $103^{\circ}$ or less). Two fruit samples were taken from each vine, a 30 -fruit sample for fruit quality and mineral nutrient concentration and a 100-fruit sample for storage studies. Fruit quality was assessed by measuring fresh weight (FW), DMC (dry weight as a percentage of FW), soluble solids concentration (SSC), flesh firmness, and flesh hue angle. DMC was determined on a $3-\mathrm{mm}$ thick equatorial slice taken from each fruit and oven-dried at $65{ }^{\circ} \mathrm{C}$ for $24 \mathrm{~h}$. SSC was measured with a refractometer (Atago Co. Ltd., Tokyo, Japan) using two drops of juice squeezed from the stem and stylar ends of each fruit combined to give one value per fruit. Flesh firmness was measured on the flat and rounded sides of each fruit using an Effegi penetrometer (Facchini, Alfonsine, Italy) with a 7.9-mm probe after a 1-mm deep slice of skin had been removed. Flesh hue angle was measured using a Minolta chromameter (Minolta, Ramsey, NJ) using a D65 light source after a 2-mm thick layer of skin and flesh had been removed.

Nitrogen $(\mathrm{N})$, phosphorus $(\mathrm{P})$, potassium $(\mathrm{K})$, sulfur $(\mathrm{S})$, calcium $(\mathrm{Ca})$, magnesium $(\mathrm{Mg})$, iron $(\mathrm{Fe})$, manganese $(\mathrm{Mn})$, zinc $(\mathrm{Zn})$, copper $(\mathrm{Cu})$, and boron $(\mathrm{B})$ were measured on plugs

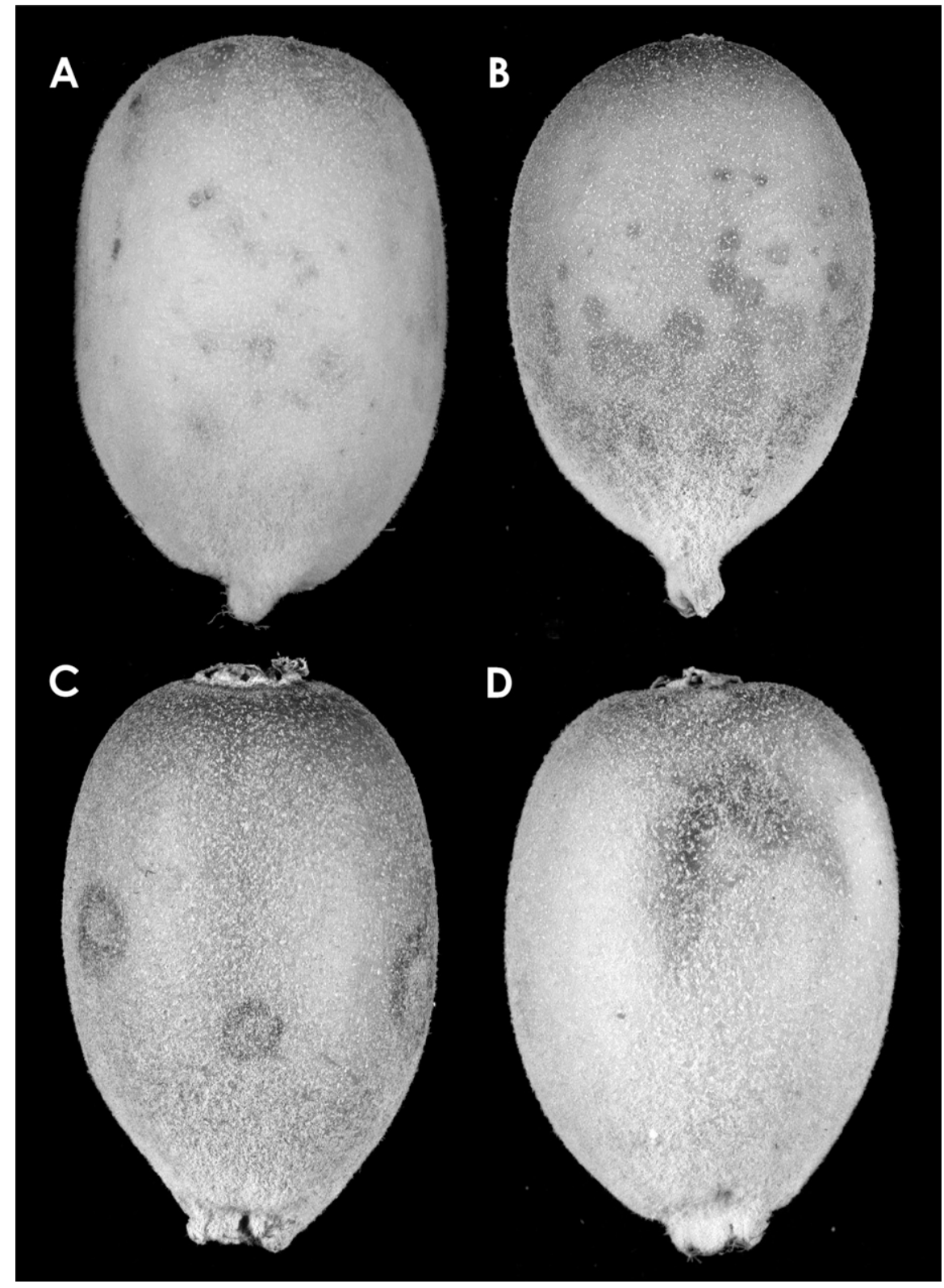

Fig. 2. External symptoms of disorders present in 'Hort16A' kiwifruit after 22 weeks in cool storage. (A) Physiological pitting, darkened "pits" usually located around the midregion of the fruit; (B) lowtemperature breakdown, skin discoloration at the beak end of the fruit; hypersensitive marks formed around: (C) "pits," and (D) an area of skin damage caused by leaf rub. 
of flesh removed from equatorial slices avoiding skin and seeds. The flesh plug samples were combined to give one bulked sample of $\approx 6$ g per vine. The samples were analyzed for $\mathrm{N}$ using combustion analysis (vario MAX CN Macro Elemental Analyser; Elementar, Hanau, Germany). The other nutrients were analyzed using nitric acid-perchloric acid digestion followed by inductively coupled plasmaoptical emission spectroscopy (Integra XL; GBC, Hampshire IL). Mineral nutrient concentrations were reported on a FW basis. The fruit for storage were placed in single-layer trays lined with polyliners and held at $0{ }^{\circ} \mathrm{C}$ for 22 weeks. After this time, disorder incidence was determined by recording the presence of rots and the storage disorders on each fruit. Three storage disorders were monitored in the fruit (Fig. 2): physiological pitting (recorded when there were more than three individual pits), low temperature breakdown (LTB; recorded when there were three or more regions of brown discoloration each greater than $1 \mathrm{~cm}^{2}$ ), and hypersensitive marks (recorded when there were at least two areas of dark discoloration greater than $1 \mathrm{~cm}^{2}$ ) on each fruit.

Statistical analysis. Treatments were arranged in a randomized design with 10 vines per treatment. Analysis of variance was carried out using GenStat Release 9.2 PC/Windows XP (Lawes Agricultural Trust Rothamsted Experimental Station, Harpenden, U.K.). Mean separation was carried out using Fisher's protected least significant difference test and results were reported as different if $P<0.05$. Percentage data were subjected to angular transformation before analysis. Data from each year were analyzed separately.

\section{Results}

Fruit numbers and cropload adjustments. Before any fruit thinning treatments were applied, the ETG vines produced $\approx 600$ to 1200 more fruit per vine than the control vines each year. The ETG vines set 2652 $( \pm 127)$ fruit per vine in $2005,3950( \pm 179)$ in 2006, and $2985( \pm 254)$ in 2007 (Fig. 3A). From 2005 to 2007, fruit numbers in the famine vines ranged from $1163( \pm 78)$ to $1630( \pm 240)$ fruit per vine. The feast vines set $\approx 1000$ more fruit per vine than the famine vines. The control vines produced similar fruit numbers to the feast vines, except in 2007 when the control vine produced $1741( \pm 99)$ fruit per vine. In 2004, fruit counts were not carried out in the feast and famine treatments. Fruit numbers were lower in both the ETG and control vines in 2007 compared with 2006. This reduction was not seen in the feast and famine vines and was probably a consequence of the higher croploads retained on the control and ETG vines in 2006 (Fig. 3B).

After fruit thinning, which was part of the treatment application, the feast vines had the lowest cropload at 750 to 1000 fruit per vine $\left(\approx 25\right.$ to 33 fruit $/ \mathrm{m}^{2}$ ), a removal of $\approx 40 \%$ of the fruit. The croploads of the control and ETG vines were adjusted to $\approx 45$ fruit $/ \mathrm{m}^{2}$ ), a removal of $17 \%$ to $40 \%$ and $47 \%$ to $82 \%$ of fruit, respectively. The famine vines received

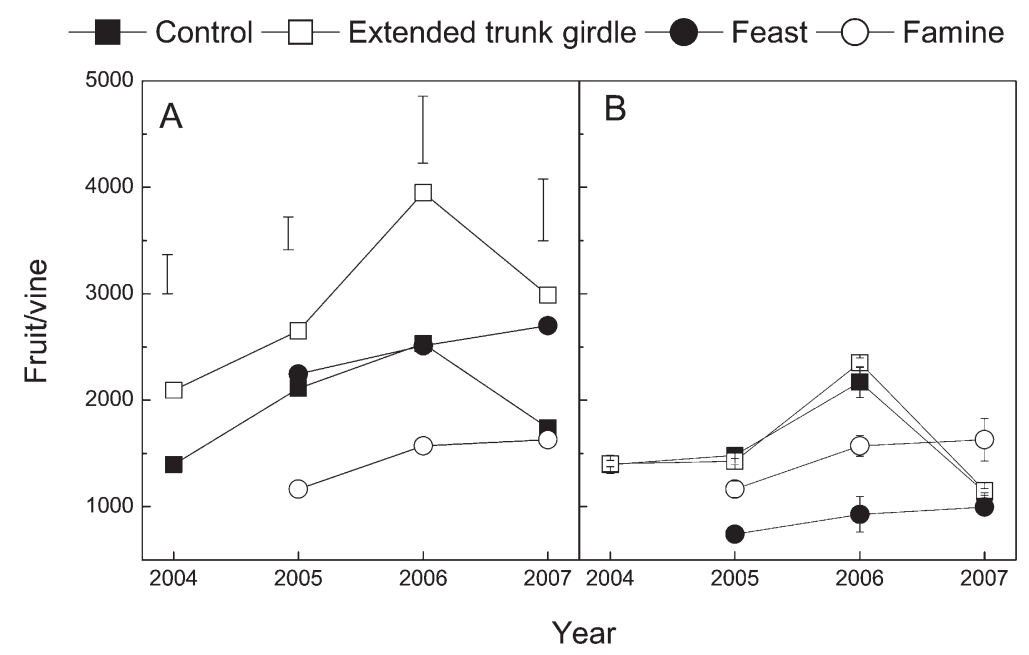

Fig. 3. Effect of vine management techniques on 'Hort16 A' kiwifruit vine productivity potential: (A) fruit number per vine set at $30 \mathrm{~d}$ after bloom over a 4-year period; (B) fruit numbers per vine after spring thinning. Treatments were control (standard orchard management practice), extended trunk girdle (ETG; where trunk was girdled in late summer and the girdled reopened over winter), feast (minimal depletion of carbohydrate reserves by low croploads and high leaf-to-fruit ratios), and famine (whole vine carbohydrate depleted by maintaining high croploads and excessive and poorly timed pruning). Vertical bars represent least significant difference $(P<0.05)$. No statistical analysis was carried out on data presented in $\mathbf{B}$ because these were part of the treatment application.

little or no fruit thinning to maintain a low leaf-to-fruit ratio (Fig. 3B).

Fruit quality at harvest. Mean FW in the feast vines was consistently 10 to $16 \mathrm{~g}$ greater than fruit from the control vines (Fig. 4A). Fruit from the famine treatment was 8 to $15 \mathrm{~g}$ smaller than fruit from the control vines except in 2007, when no difference was detected. The ETG treatment did not affect fruit FW compared with the control fruit except in 2006 when the ETG fruit were $6 \mathrm{~g}$ larger than the control fruit. The ETG treatment increased fruit $\mathrm{DMC}$ by $0.9 \%$ to $1.7 \%$ units over the control fruit each year (Fig. 4B). Fruit from the feast vines had higher DMC than the control vines in 2005 and 2007 but not in 2006. Fruit from the famine vines had lower DMC than the control vines except in 2007 when DMC was the same in the control and famine vines. Fruit from the famine vines had lower SSC and firmer, greener flesh (higher hue ${ }^{\circ}$ ) than fruit from the other treatments (Figs. 4C-E). Fruit from the ETG and feast treatments generally had higher SSC and softer, more yellow flesh than the control fruit, although these results were not consistent across seasons.

Fruit mineral concentrations. Seasonal effects were generally larger than treatment effects, and few consistent treatment effects were observed (Fig. 5). Nitrogen concentrations were consistently higher in the feast fruit than the famine fruit. Fruit concentrations of $\mathrm{P}$ and $\mathrm{S}$ were generally lowest in the ETG fruit, except for S in 2006 when no treatment effects were detected. Any other treatment differences were inconsistent; in 2006, for example, $\mathrm{Ca}$ concentrations were higher in the famine fruit than fruit from other treatments (Fig. 5). This effect was not detected in 2005 or 2007 . The treatments did not consistently affect fruit concentrations of $\mathrm{K}, \mathrm{Fe}, \mathrm{Zn}$, $\mathrm{Cu}$, or $\mathrm{B}$ (data not presented).
Fruit storage performance. There was wide seasonal variation in the proportion of fruit affected by LTB and physiological pitting (Table 1). The incidence of LTB was highest in 2007 with $19 \%$ of fruit affected and lowest in $2006(0.6 \%)$. Approximately $5 \%$ to $7 \%$ of fruit had physiological pitting in 2005 and 2006 with less than $1 \%$ incidence in 2007 . When LTB was prevalent, fruit from the famine treatment were most severely affected and fruit from the feast and ETG were least affected. Conversely, physiological pitting was more prevalent in fruit from the feast and ETG treatments; fruit from the famine treatment were the least affected. The presence of hypersensitive marks in the fruit showed less extreme seasonal variation with $6.4 \%$ to $10.5 \%$ of fruit affected each season. In 2006, more hypersensitive marks were visible in fruit from the ETG vines than the remaining vines, and in 2007, both the ETG and famine fruit had higher incidence of hypersensitive marks than the control and feast vines. No treatment effects were detected in 2005 (Table 1).

\section{Discussion}

After three consecutive seasons, the treatments affected vine productivity, fruit FW and DMC, fruit maturity, and disorder incidence but had inconsistent effects on concentrations of the inorganic nutrients in fruit.

High croploads and partial defoliation reduced return bloom in 'Hayward' kiwifruit (Buwalda and Smith, 1990; Cooper and Marshall, 1991). It is therefore not surprising that return bloom was decreased by the famine treatment. The famine vines produced on average $\approx 1000(\approx 42 \%)$ fewer fruit than the feast vines, a difference that remained relatively consistent between the two treatments 

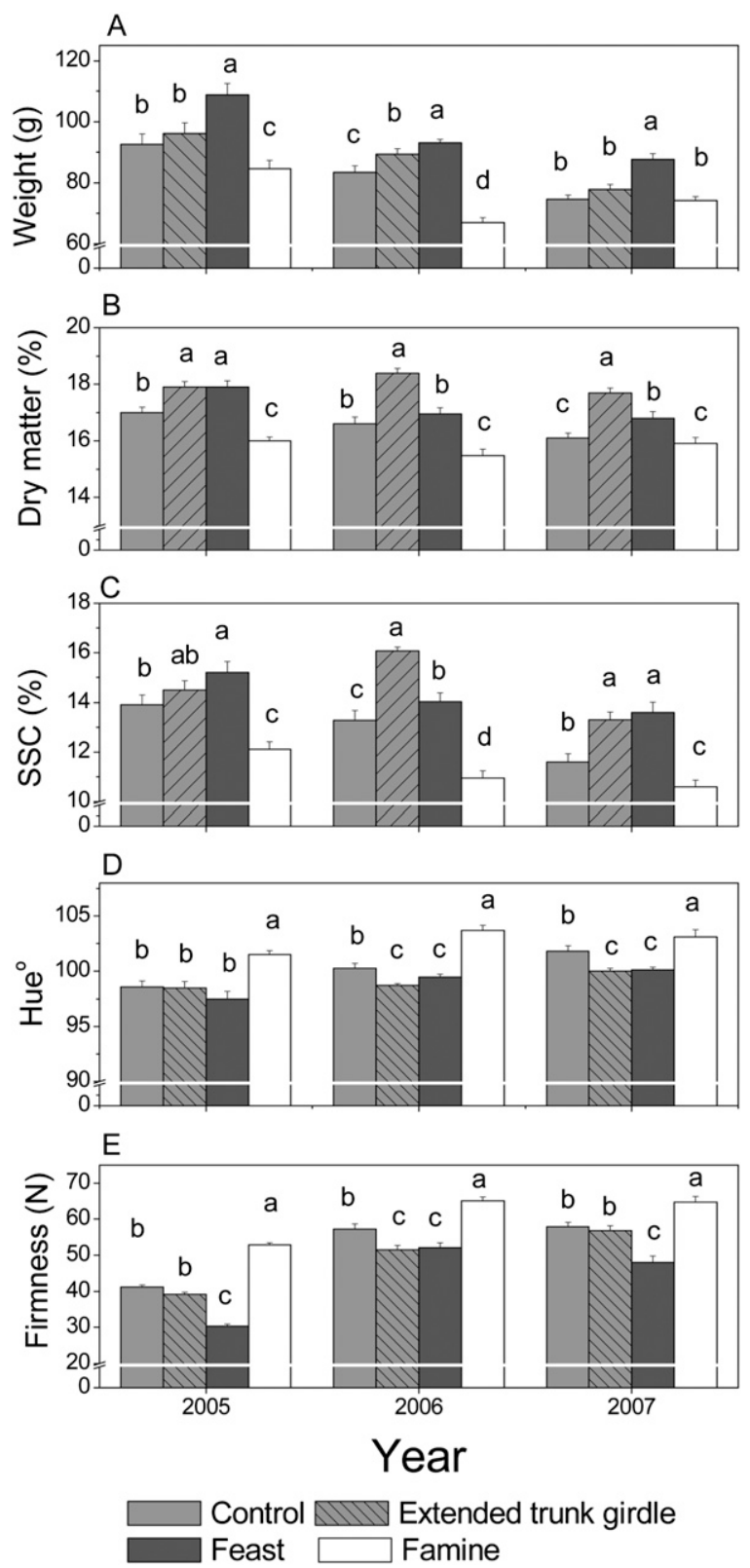

Fig. 4. Effect of vine treatments on fruit quality attributes at harvest. Data are means $\pm S E(n=10)$. Within any year, bars with different letters are significantly different $(P<0.05)$ Treatments were control (standard orchard management practice), extended trunk girdle (ETG; where trunk was girdled in late summer and the girdled reopened over winter), feast (minimal depletion of carbohydrate reserves by low croploads and high leaf-to-fruit ratios), and famine (whole vine carbohydrate depleted by maintaining high croploads and excessive and poorly timed pruning).

across the three seasons (Fig. 3A). The feast vines, which carried reduced croploads and greater leaf numbers than the control vines, did not have higher return bloom than the control vines (except in 2007 when we overcropped the control vines). It may be that increased shading generated by the higher leaf area in the feast vines countered any benefit of the reduced cropload on return bloom. In 'Hayward' vines, canes growing in shaded positions are less productive than well-exposed canes (Grant and Ryugo, 1984; Snelgar and Hopkirk, 1988).

The ETG vines produced higher fruit numbers than the control vines, by $25 \%, 55 \%$, and $71 \%$ in 2005,2006 , and 2007 , respectively. Unlike the feast and famine treatments, in which differences in fruit set occurred in the first season and remained relatively constant in subsequent seasons, the difference between the ETG and control vines increased each season. Without thinning to a standard cropload of $\approx 45$ fruit $/ \mathrm{m}^{2}$, it is unlikely that the ETG vines could carry croploads equivalent to 90 to $130 \mathrm{fruit} / \mathrm{m}^{2}$ without seriously compromising fruit size. The ETG and feast treatments increased fruit DMC and advanced maturity relative to fruit from control vines. Fruit maturity attributes are affected by different canopy management techniques in a range of crops. Reduced croploads resulted in advanced fruit maturity in apple (Palmer et al., 1997) and peach (Siham et al., 2005). Excessive shading delayed maturity in 'Hayward' kiwifruit, measured by SSC (Tombesi et al., 1993), whereas more open canopies generated by leader pruning resulted in fruit with higher SSC (Miller et al., 2001). In our famine treatment, a combination of excessive pruning and high croploads resulted in delayed maturity relative to fruit from the control vines. Any advantage conferred by the more open canopy was countered by apparent competition between fruit and the vigorous shoot growth stimulated by the excessive pruning treatment; the result was fruit with lower DMC.

The incidence of physiological pitting and LTB was associated with fruit maturity at harvest, fruit from treatments that were more mature at harvest were more likely to develop physiological pitting, and fruit that were less mature at harvest were more likely to develop LTB. This supports previous findings by Clark et al. (2004) that fruit that were affected by LTB contained less dry matter, had appreciably lower SSC, and greener flesh color than their unaffected counterparts. In this experiment, we did not harvest each treatment at the same maturity; this approach could offer additional insight into fruit maturation effects. There was no evidence that fruit concentrations of inorganic nutrients were associated with either LTB or pitting incidence despite previous findings with 'Hayward' kiwifruit that low fruit $\mathrm{Ca}$ concentrations were associated with the incidence of both physiological pitting (Ferguson et al., 2003) and LTB (Gerasopoulos and Drogoudi, 2005).

Hypersensitive marks are areas of cell death that form at the point of pathogen ingress and which correlate with the exhibition of resistance (Mur et al., 2007). In kiwifruit, hypersensitive marks appear to be linked to a range of factors, including insect damage, sunburn, and rots. We found no association between the incidence of hypersensitive marks and fruit maturity at harvest. In 2007, for example, the ETG and famine fruit had higher incidence of hypersensitive marks. Skin damage caused by the treatment application (leaf removal in the famine treatment) combined with the higher degree of sun exposure experienced by fruit from the ETG and famine fruit may be partly responsible for the higher incidence of hypersensitive marks in these two treatments.

We expected that long-term application of ETG or famine-type treatments would impair root function by affecting root reserves or root turnover, thereby reducing the root uptake of water and soil nutrients. After 3 years, we have seen no evidence of decline in fruit nutrient concentrations and little evidence of treatment-induced differences in fruit nutrient status with the exception that $\mathrm{N}$ concentrations were consistently lower in the famine fruit than the feast fruit. Arakawa et al. (1997) reported that trunk girdling $40 \mathrm{~d}$ after midbloom reduced $\mathrm{Ca}$ concentrations in mature apple fruit relative to ungirdled controls. In our vines, the girdle was applied $\approx 120 \mathrm{~d}$ after midbloom, which is after $\mathrm{Ca}$ accumulation in kiwifruit has more or less ceased (Clark and Smith, 1988). It is possible that nutrient uptake was affected by 


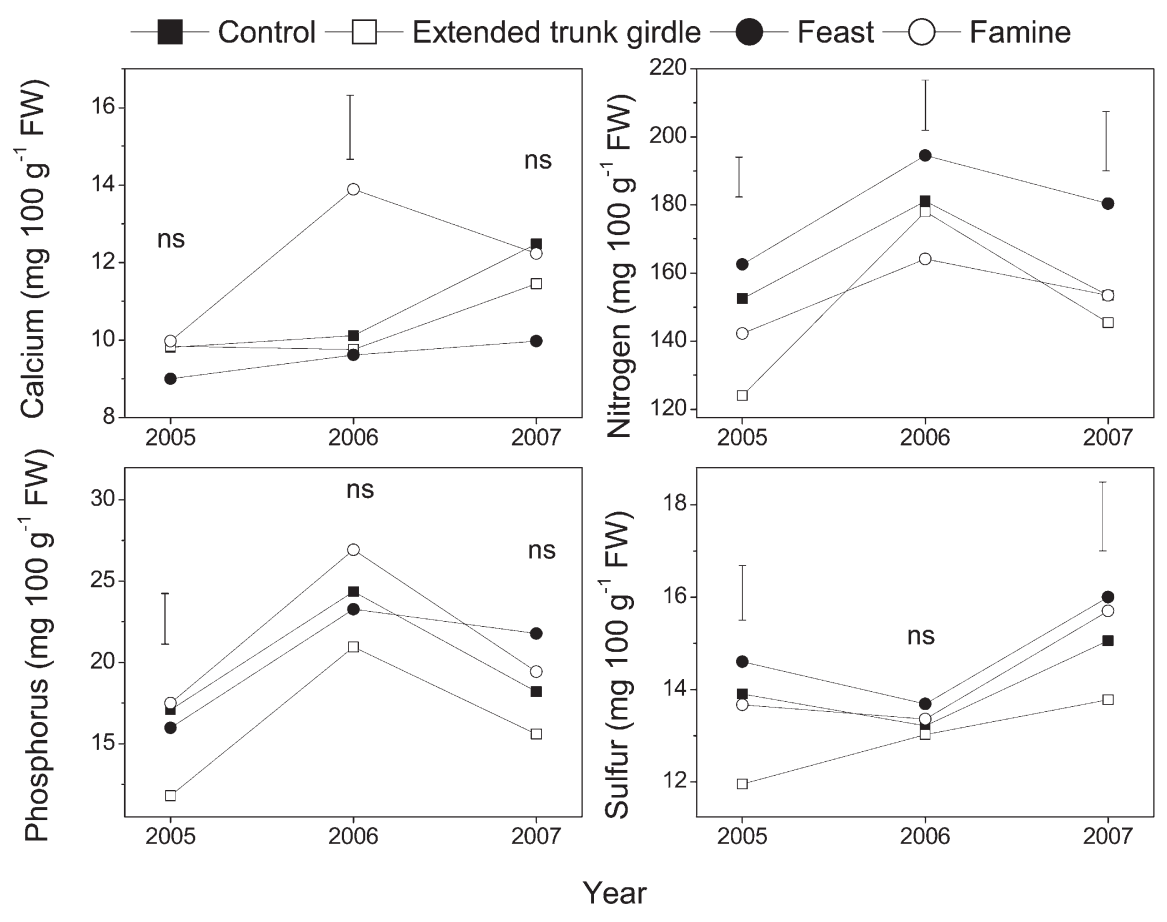

Fig. 5. Effect of vine treatments on fruit calcium, nitrogen, phosphorus, and sulfur concentrations. Data are means $(\mathrm{n}=10)$. Vertical bars represent least significant difference $(P<0.05)$. Treatments were control (standard orchard management practice), extended trunk girdle (ETG; where trunk was girdled in late summer and the girdle reopened over winter), feast (minimal depletion of carbohydrate reserves by low croploads and high leaf-to-fruit ratios), and famine (whole vine carbohydrate depleted by maintaining high croploads and excessive, poorly timed pruning).

Table 1. Effect of vine management treatments on fruit storage disorders in 'Hort16A' kiwifruit.

\begin{tabular}{|c|c|c|c|c|c|c|c|c|c|}
\hline \multirow[b]{3}{*}{ Treatment $^{z}$} & \multicolumn{9}{|c|}{ Proportion of fruit (\%) } \\
\hline & \multicolumn{3}{|c|}{ Low temp breakdown } & \multicolumn{3}{|c|}{ Physiological pitting } & \multicolumn{3}{|c|}{ Hypersensitive marks } \\
\hline & 2005 & 2006 & 2007 & 2005 & 2006 & 2007 & 2005 & 2006 & 2007 \\
\hline Control & $2.1 \mathrm{~b}^{\mathrm{y}}$ & 0.2 & $23.1 \mathrm{~b}$ & $3.7 \mathrm{~b}$ & $3.7 \mathrm{~b}$ & 0.3 & 6.6 & $6.4 \mathrm{~b}$ & $3.9 \mathrm{~b}$ \\
\hline ETG & $4.3 \mathrm{~b}$ & 0.1 & $12.0 \mathrm{c}$ & $7.1 \mathrm{a}$ & $12.6 \mathrm{a}$ & 0.0 & 12.9 & $14.8 \mathrm{a}$ & $11.0 \mathrm{a}$ \\
\hline Feast & $0.3 \mathrm{~b}$ & 0.1 & $5.2 \mathrm{c}$ & $10.7 \mathrm{a}$ & $9.8 \mathrm{a}$ & 0.3 & 9.9 & $4.6 \mathrm{~b}$ & $3.1 \mathrm{~b}$ \\
\hline Famine & $16.1 \mathrm{a}$ & 1.8 & $36.6 \mathrm{a}$ & $1.2 \mathrm{~b}$ & $0.1 \mathrm{~b}$ & 0.0 & 12.8 & $7.4 \mathrm{~b}$ & $11.0 \mathrm{a}$ \\
\hline
\end{tabular}

${ }^{\mathrm{z}}$ Control $=$ standard orchard practices; $\mathrm{ETG}=$ extended trunk girdling where vines were girdled in late summer and over winter; feast $=$ minimal depletion of carbohydrate reserves, manipulated using low croploads and a high ratio leaf to fruit; famine = whole-vine carbohydrates depleted by maintaining high croploads and using excessive and poorly timed pruning.

y Different letters within columns denote significant differences among means (Fisher's protected least significant difference test, $P<0.05)$.

the treatments but was expressed in other parts of the vine such as leaves.

We conclude that whole-vine treatments that allocate a greater proportion of carbohydrates to fruit than to root or shoot growth also affect vine productivity and fruit quality. Extended trunk girdling produced fruit with higher DMC and typically advanced maturity compared with ungirdled control vines carrying the same cropload and harvested on the same date. Fruit from the ETG vines were more susceptible to physiological pitting and less susceptible to LTB than fruit from the control vines. Each season the ETG vines became relatively more productive than the control vines, resulting in increasingly large numbers of fruitlets being thinned to obtain realistic croploads. In contrast, the relatively high croploads, low leaf numbers, and increased competition between growing shoots and fruit in the famine vines reduced vine productivity by $\approx 40 \%$ compared with vines
Candolfi-Vasconcelos, M.C. and W. Koblet. 1990. Yield, fruit quality, bud fertility and starch reserves of the wood as a function of leaf removal in Vitis vinifera-Evidence of compensation and stress recovering. Vitis 29:199221.

Clark, C.J., V.A. McGlone, N.H. De Silva, M.A. Manning, J. Burdon, and A. Mowat. 2004. Prediction of storage disorders of kiwifruit (Actinidia chinensis) based on visible-NIR spectral characteristics at harvest. Postharvest Biol. Technol. 32:147-158.

Clark, C.J. and G.S. Smith. 1988. Seasonal accumulation of mineral nutrients by kiwifruit 2 . Fruit. New Phytol. 108:399-409.

Clark, C.J. and G.S. Smith. 1992. Seasonal dynamics of biomass and mineral nutrient partitioning in mature kiwifruit vines. Ann. Bot. (Lond.) 70: 229-237.

Cooper, K.M. and R.R. Marshall. 1991. Croploading and canopy management. Acta Hort. 297: 501-508.

Cutting, J.G.M. and M.C. Lyne. 1993. Girdling and the reduction in shoot xylem sap concentrations of cytokinins and gibberellins in peach. J. Hort. Sci. 68:619-626.

Davison, R.M. 1990. The physiology of the kiwifruit vine. p. 150. In: Warrington, I.J. and G.C. Weston (eds.). Kiwifruit science and management. Ray Richardson Publisher and the New Zealand Society for Horticultural Science, Auckland, New Zealand.

Ferguson, A.R. 1990. The genus Actinidia, p. 15. In: Warrington, I.J. and G.C. Weston (eds.). Kiwifruit science and management. Ray Richardson Publisher and the New Zealand Society for Horticultural Science, Auckland, New Zealand.

Ferguson, I.B., T.G. Thorp, A.M. Barnett, L.M. Boyd, and C.M. Triggs. 2003. Inorganic nutrient concentrations and physiological pitting in 'Hayward' kiwifruit. J. Hort. Sci. Biotechnol. 78:497-504.

Gerasopoulos, D. and P.D. Drogoudi. 2005. Summerpruning and preharvest calcium chloride sprays affect storability and low temperature breakdown incidence in kiwifruit. Postharvest Biol. Technol. 36:303-308.

Goren, R., M. Huberman, and E. Goldschmidt. 2004. Girdling: Physiological and horticultural aspects. Hort. Rev. 30:1-36.

Grant, J.A. and K. Ryugo. 1984. Influence of withincanopy shading on fruit size, shoot growth, and return bloom in kiwifruit. J. Amer. Soc. Hort. Sci. 109:799-802.

Harker, F.R., B.T. Carr, M. Lenjo, E.A. MacRae, W.V. Wismer, K.B. Marsh, M. Williams, A. White, C.M. Lund, S.B. Walker, F.A. Gunson, and R.B. Pereiraa. 2009. Consumer liking for kiwifruit flavour: A meta-analysis of five studies on fruit quality. Food Qual. Prefer. 20:30 41.

Harrell, D.C. and L.E. Williams. 1987. The influence of girdling and gibberellic acid application at fruitset on Ruby Seedless and Thompson Seedless grapes. Amer. J. Enol. Viticult. 38:8388.

Arakawa, O., K. Kanno, A. Kanetsuka, and Y. Shiozaki. 1997. Effects of girdling and bark inversion on tree growth and fruit quality of apple. Acta Hort. 451:579-585.

Boyd, L.M., A.M. Barnett, C. Civolani, and E. Fini. 2010. Whole plant excavations to determine nutritional requirements in 'Hort16A' kiwifruit vines. Acta Hort. 868:171-176.

Buwalda, J.G. and G.S. Smith. 1990. Effects of partial defoliation at various stages of the growing season on fruit yields, root growth and return bloom of kiwifruit vines. Sci. Hort. 42:29-44.

Heim, G., J.J. Landsberg, R.L. Watson, and P. Brain. 1979. Eco-physiology of apple trees: Dry matter production and partitioning by young Golden Delicious apple trees in France and England. J. Appl. Ecol. 16:179194.

Koch, K.E. 1996. Carbohydrate-modulated gene expression in plants. Annu. Rev. Plant Physiol. Plant Mol. Biol. 47:509-540.

Miller, S.A., F.D. Broom, T.G. Thorp, and A.M. Barnett. 2001. Effects of leader pruning on vine 
architecture, productivity and fruit quality in kiwifruit (Actinidia deliciosa cv. Hayward). Sci. Hort. 91:189-199.

Mur, L.A.J., P. Kenton, A.J. Lloyd, H. Ougham, and E. Prats. 2007. The hypersensitive response; the centenary is upon us but how much do we know? J. Expt. Bot. 59:501-520.

Palmer, J.W., R. Giuliani, and H.M. Adams. 1997. Effect of crop load on fruiting and leaf photosynthesis of 'Braeburn'/M.26 apple trees. Tree Physiol. 17:741-746.

Siham, M., C. Bussi, F. Lescourret, M. Genard, R Habib, and J. Gilreath. 2005. Pruning intensity and fruit load influence on vegetative and fruit growth in 'Alexandra' peach. Proc. Florida State Hort. Soc. 118:266-269.

Snelgar, W.S. and G. Hopkirk. 1988. Effect of overhead shading on yield and fruit quality of kiwifruit (Actinidia deliciosa). J. Hort. Sci. 63: 731-742.

Tombesi, A., E. Antognozzi, and A. Palliotti. 1993. Influence of light exposure on characteristics and storage life of kiwifruit. N. Z. J. Crop Hort. Sci. 21:87-92.

Valladares, F., E. Giannoli, and J.M. Gomez. 2007. Ecological limits to plant phenotypic plasticity. New Phytol. 176:749-793. 